W99-26

\title{
Self-Regulation and Social Welfare: The Political Economy of Corporate Environmentalism
}

by

\author{
John W. Maxwell* \\ Thomas P. Lyon ${ }^{* *}$ \\ Steven C. Hackett ${ }^{*+*}$
}

September 1999

(C) 1999 by authors

\author{
WONX

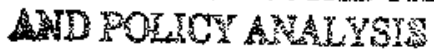

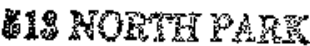

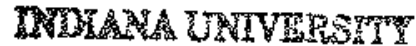

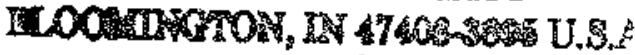

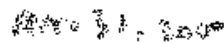

\begin{abstract}
We extend the economic theory of regulation to allow for strategic self-regulation that preempts political action. When political "entry" is costly for consumers, firms can deter it through voluntary restraints. Unlike standard entry models, deterrence is achieved by overinvesting to raise the rival's welfare in the event of entry. Empirical evidence on releases of toxic chemicals shows that an increased threat of regulation (as proxied by increased membership in conservation groups) indeed induces firms to reduce toxic releases. We establish conditions under which self-regulation, if it occurs, is a Pareto improvement once costs of influencing policy are included.
\end{abstract}

JEL Codes: D72, K32, L51, Q28

Keywords: Regulation, environment, self-regulation, political economy

Forthcoming in the Journal of Law and Economics. We would like to thank Hejoon Kang, Roger Noll, Peter Pashigian, Sam Peltzman, Juergen von Hagen, Michael Waldman, an anoymous referee and seminar participants at Chicago, Indiana, the London School of Economics, Northwestern, Penn State, Purdue, Tennessee, the University of Siena and the American, Western, Eastern and Canadian Economic Association meetings for helpful comments. We also thank Chris Decker for expert research assistance. Lyon gratefully acknowledges the Indiana University School of Business, the I.U. School of Business Alumni Association, and the University of Chicago's George J. Stigler Center for the Study of the Economy and the State for financial support.

* Kelley School of Business, Indiana University.

** Kelley School of Business, Indiana University.

*** School of Business and Economics, Humboldt State University.

\section{Workshop in Political Theory and Policy Analysis}

Indiana University, 513 North Park Bloomington, IN 47408-3895 USA
Phone: (812) 855-0441

Fax: (812) $855-3150$ workshop@indiana.edu www.indiana.edu/ workshop 


\section{INTRODUCTION}

"While some of the environmental changes now emerging in corporate America are genuine and welcome, a good many are superficial, some are downright diversionary, and a few are being specifically designed to preempt more stringent public policies from emerging."

Brent Blackwelder, President Friends of the Earth ${ }^{1}$

"In an effort to head off legal restrictions on privately traded derivatives, six of Wall Street's biggest securities firms have agreed to voluntarily tighten their controls on the most hotly contested aspects of their derivatives sales and trading."

Wall Street Journal

March 9, $1995^{2}$

"In today's society any industry as conspicuous as the major home appliance industry is continually faced with the threat of government regulation. In my opinion, the only way to avoid government regulation is to move faster than the government. The alternative to government regulation is judicious self-regulation."

Herbert Phillips, Technical Director

Association of Home Appliance Manufacturers ${ }^{3}$

To economists, "regulation" means restraints imposed upon firms by government. In many cases, however, firms voluntarily restrain their own conduct; they "self-regulate." ${ }^{4}$ Examples include establishment of financial exchanges, licensing of professionals, setting of safety standards, control of entertainment content, advertising restrictions, and voluntary pollution abatement. While self-regulation may have a variety of motives, ${ }^{5}$ in this paper we model it as a way to preempt government regulation, examining the conditions under which preemption is possible and, if it occurs, its welfare consequences. We present our analysis in the context of "corporate environmentalism," i.e. voluntary adoption of cleaner products or processes, but it should be clear from the above examples that the basic story has broader applicability.

Some intriguing preliminary evidence of self-regulation is presented in Figure 1, which shows-for the U.S. over the period 1988-1992 — total releases of seventeen selected toxic chemicals against the dollar 
value of shipments from the seven main industries emitting these chemicals. While shipments have risen, toxic emissions have dropped off markedly. In fact, the aggregate emissions of these chemicals fell by $40 \%$ from 1988 to 1992 . Changes in government regulation are not driving the reductions, as these emissions are legal. This paper presents a theory of self-regulation in which this voluntary abatement can be explained by increases in the threat of federal and/or state regulation.

While corporate environmentalism is on the rise, it remains controversial. ${ }^{6}$ Critics argue selfregulation provides less environmental protection than does government regulation. The "Big Three" automakers' Vehicle Recycling Partnership is limited to creating labeling standards for plastic components, and falls well short of the German program of comprehensive automotive disassembly and reuse. Selective cutting in old growth forests is more environmentally friendly than clear cutting, but many argue that such forests should not be cut at all. The "Responsible Care" program initiated by the Chemical Manufacturers Association (CMA) may be used as a rationale for refusing to adopt more stringent environmental practices; according to Barnard (1990, p. 5), at least one CMA member—Union Carbide—-has already done just that. Such considerations raise questions about how social welfare is affected when selfregulation preempts government action. Indeed, these question are the primary motivation for the model we develop. Welfare concerns are likely to become increasingly important, since as Walley and Whitehead (1994) point out, "win-win" situations—in which pollution prevention raises both corporate profits and consumer well-being — are increasingly difficult to find. ${ }^{7}$ One of the striking features of our model is the strong welfare analysis that emerges.

We model self-regulation and social welfare in a three-stage game where Cournot oligopolists face the possibility of stricter pollution abatement regulations. Following Becker (1983), we model these regulations as arising from a political influence game between consumers and firms, with consumers favoring stricter abatement regulations than do firms. ${ }^{8}$ Following Stigler (1971) and Peltzman (1976), we assume it is costly for interested parties to organize themselves to enter the political process and to influence 
policymakers once involved in the political process. In the first stage of our game, symmetric firms choose (possibly zero) levels of voluntary abatement. In the second stage, identical consumers observe the voluntary abatement activity and determine whether to enter the influence game; if they do so, they and the firms exert pressure on government for their desired level of regulations, and an abatement policy is determined. In the third stage, firms play a Cournot production game.

From a methodological viewpoint, our analysis extends the economic theory of regulation in two directions. ${ }^{9}$ First, by adding an initial stage of voluntary actions by firms, we allow for the possibility of strategic self-regulation that preempts government action. As a result, we obtain some striking parallels and contrasts with the standard industrial organization literature, which typically takes regulation as either exogenously fixed or as a set of controls to be optimized. Second, by modeling explicitly the dimension of product quality (in this case, pollution abatement), we can address directly issues of regulatory efficiency discussed only informally by Becker.

The key positive implication of our model is that an increased threat of government regulation induces firms to voluntarily reduce pollution emissions. We examine empirically the massive cuts in U.S. toxic chemical releases since 1988, (illustrated in Figure 1), and the role of potential regulatory entry in stimulating these cuts. We investigate state-level variation in the threat of regulation using a panel data on releases of toxic chemicals over the period from 1988 to 1992. Our most significant finding is that states with higher initial levels of toxic emissions and larger environmental group membership reduced toxic emissions more rapidly. In this situation, firms have relatively low marginal abatement costs, consumers value abatement highly, and consumer organizing costs are low. Since the threat of mandatory regulation is high while the marginal cost of self-regulation is relatively low, it makes good sense for firms to engage in voluntary emissions reductions.

In addition to the foregoing positive predictions and empirical results, we also derive some striking normative results. We show that interest group rivalry (the influence game) produces weaker pollution 
regulation than is socially optimal. Nevertheless, we show that when the costs of influencing policy are included, $\left({ }^{\mathrm{f}}\right.$ voluntary abatement occurs then it represents a Pareto improvement over the status quo. More importantly, social welfare under preemption also Pareto-dominates that which would have arisen from the influence game, had it been played.

Our analysis has two implications for public policy. First, it lends support to an antitrust policy allowing industries to coordinate on voluntary abatement strategies, since such coordination increases beneficial self-regulation. Second, it raises questions about government financing of consumer intervention into the political process: if consumer involvement becomes too easy, firms may eschew voluntary abatement, with the result that both they and consumers are worse off than when consumer involvement was difficult.

Before proceeding, we briefly contrast our paper with related work in the literature. ${ }^{10}$ Despite the ubiquity of self-regulation, the phenomenon has received little attention from economists. There have been several interesting case studies and institutional analyses, ${ }^{11}$ and a few papers that apply a vertical product differentiation framework to model the idea that firms voluntarily reduce pollution to attract "green" consumers. ${ }^{12}$ Arora and Cason (1995) study empirically which types of firms are most likely to participate in government programs aimed at voluntary abatement.

In a more strategic vein, Braeutigam and Quirk (1984) and Lyon (1991) analyze models wherein a regulated firm voluntarily reduces its price to avoid a rate review that would cut rates even further. Similarly, Glazer and McMillan (1992) show that the threat of price regulation may induce a monopolist to price below the unregulated monopoly level. Our analysis is related to these earlier strategic analyses, but richer in several important respects. We consider an oligopolistic industry in which consumers have both price and non-price (e.g., pollution) concerns. We model explicitly the incentives of interest groups (producers and consumers) to expend resources on lobbying for their preferred policies, and allow the stringency of regulations to be determined endogenously. We complement our theoretical analysis with 
empirical evidence from a unique panel dataset that provides support for our theoretical predictions.

Finally, we assess the social welfare implications of regulatory preemption, and address policy questions about appropriate antitrust treatment of self-regulation and about government subsidy of consumer intervention in the political process.

Our results are also related to the literature on entry deterrence. ${ }^{13}$ In a sense, our oligopoly invests in pollution control to deter "entry" by consumers to the influence game. Unlike standard entry deterrence models, however, here the "fat cat" strategy—under which investment raises the rival's welfare in the event entry occurs-is effective in preempting entry. ${ }^{14}$ The reason is that in ordinary deterrence games staying out yields the potential entrant a fixed reservation level of profits. Here, in contrast, consumers' utility of staying out of the influence game rises as firms invest. Welfare-enhancing preemption is possible because as voluntary abatement increases, consumers' utility of staying out rises faster than the utility of entering. ${ }^{15}$

The remainder of the paper is organized as follows. Section II presents the model, while Section III develops two key propositions about the conduct of firms and of consumers. Section IV establishes welfare results and explores policy implications. Section $\mathrm{V}$ examines our positive hypotheses using cross-sectional data on the fifty U.S. states, while section VI concludes and discusses directions for future research. All proofs are presented in the Appendix.

\section{THE MODEL}

In this section we present a three-stage model of voluntary pollution control. For simplicity, we assume symmetric firms and we do not discount payoffs over time. The sequence of moves in the model is as follows. First, firms choose a level (possibly zero) of voluntary pollution control that is assumed to be binding. For example, it could be built into the production technology, or firms could sell a conservation easement to an environmental group (e.g., the group buys the right to dictate a production technology to the firms, such as selective rather than clear-cut logging), or irrevocably link their image to voluntary abatement 
through advertising. Second, firms and consumers (who receive utility from the good but disutility from pollution) engage in interest-group rivalry for the purpose of influencing pollution control policy. Third, after pollution control policy has been determined, firms produce and sell output in a Cournot oligopoly. We focus on the case in which consumers will successfully lobby for new regulations if the firms take no voluntary action, since there is no other motive for voluntary action in the model. As is standard in multistage games, subgame perfection is achieved by solving the model in reverse chronological order, hence the exposition below is presented from a backward-induction perspective.

\section{Stage 3: Output Market Equilibrium}

In the last stage of the game, $N^{f}$ identical firms engage in Cournot-style quantity rivalry in an industry featuring pollution externalities. ${ }^{16}$ Firm $i$ chooses an output level $q_{i}$, and the firms face industry demand curve $P(Q)$, where $Q=\Sigma_{i} q_{i}$; we will also use the notation $Q_{-i}=\sum_{j+i} q_{j}$. Firms install a pollution control input, in the amount $Z$, which is the sum of a voluntary choice $Z^{V}$ from stage 1 and mandatory control level $Z^{M}$ from stage 2 of the game. ${ }^{17}$ Firms are then confronted with per-unit output cost $c(Z)$ that is constant with regard to output, and a fixed capital cost $k(Z)$, both of which are increasing and convex in $Z$. In order to focus on the strategic aspects of voluntary abatement, we assume the costs of self-regulation and government regulation are equal, and are only a function of $Z^{18}$ Given $Q_{-i}$, firm $i$ 's problem is to

$$
\max _{q_{i}}\left[P\left(Q_{-i}+q_{i}\right)-c(Z)\right] q_{i}-k(Z)
$$

In the symmetric Coumot-Nash equilibrium, ${ }^{19}$ firms have equal outputs, defined by

$$
q_{i}^{*}=-\frac{\left[P\left(Q^{*}\right)-c(Z)\right]}{P^{\prime}\left(Q^{*}\right)}
$$


aggregate quantity traded is $Q^{*}=N^{f} q_{i}^{*}$, and the market clearing price is $\mathrm{P}\left(\mathrm{Q}^{*}\right)$. Henceforth we shall drop the subscript " $i$, as in equilibrium all firms are identical. There should thus be no confusion in proceeding to use subscripts to indicate derivatives. Equilibrium earnings per firm, given $Q^{*}$, are $\pi^{N}(Z)$, where the superscript " $\mathrm{N}$ " indicates no influence costs are included at this stage. Note that our convexity assumptions on costs imply $\pi_{z}^{N}=-c_{Z} q^{*}-k_{z}<0$ and $\pi_{z z}^{N}=-c_{z z} q^{*}-k_{z z}<0$.

\section{Stage 2: Influence Game}

Following Becker (1983) we model pollution-control policy as the outcome of rival "influence inputs" being transformed through political institutions. In our model there are two interest groups: one is made up of the $N^{f}$ firms whose costs are increased by additional pollution-control restraints, while the other is made up of $N^{c}$ consumers who purchase the good produced by the firms and who also have disutility over pollution emitted by the firms. All individuals and firms allocate influence inputs noncooperatively. ${ }^{20}$ Firms, if they enter the influence game, always attempt to influence policy makers to reduce mandatory pollution control (the per-firm resources they allocate for this purpose are referred to by the variable $l$ ). ${ }^{21}$ While consumers care about their consumer surplus from buying the good produced by firms, and thus oppose higher prices, they also have disutility over pollution. Thus it is possible for firms to choose a level of voluntary abatement sufficiently high that consumers would actually prefer less than the voluntary level of pollution control. This is never profitable for firms, however, so consumers--if they enter the political process--always allocate resources (in the amount of $m$ per person) to influence policy makers to choose more pollution control.

Following Stigler (1971) and Peltzman, (1976) we assume that consumers wishing to influence the process of policy formation must bear in the aggregate a fixed cost $F\left(N^{c}\right)$; each of the identical consumers then bears a cost $f\left(N^{c}\right)=F\left(N^{c}\right) / N^{c}$ if the consumer group enters the influence game. In the present context, individuals must inform themselves of the implications of pollution control for their well-being, ${ }^{22}$ and of the 
efficacy of various feasible policy remedies. Individuals of similar interests must then coordinate on a mutual lobbying strategy. We will refer to these various costs collectively as organizing costs. Firms face similar tasks, but their organizing costs are typically less than those of consumers, since assessing the costs of regulation to the firm is usually much easier than assessing the health and aesthetic benefits to consumers, and the number of firms in an industry is typically very small relative to the number of consumers. Without loss of generality, then, we normalize firms' cost of organizing to zero.

Since the $N^{f}$ firms are identical, aggregate firm resources allocated to political pressure are $L=N^{f} l$. Similarly, the $N^{c}$ consumers devote $M=N^{c} m$ aggregate resources to pressure activities if they choose to incur the fixed cost of entering the political process. We represent the influence process through a function $Z^{M}(M, L)$ which gives the mandatory abatement level as a function of influence inputs; when the firm undertakes voluntary abatement, total abatement is then $Z(M, L)=Z^{V}+Z^{M}(M, L) .{ }^{23}$ We assume $Z_{M}>0$, $Z_{L}<0, Z_{M M}<0$, and $Z_{L L}>0$. (We will often suppress the dependence of $Z$ on influence for notational ease.)

Consider a representative firm's optimization problem in the influence game. Firm $i$, given the influence choices of the other parties ( $M$ by consumers, $L_{-i}$ by the other firms), must choose influence input $l$ to maximize:

$$
\pi^{N}\left(Z^{V}+Z^{M}\left[M, L_{-i}+l\right]\right)-l
$$

A firm's optimal choice of $l$ is given by the following equation:

$$
\pi_{z}^{N} Z_{l}=1
$$

Consumers are utility maximizers, and choose their per-person lobbying expenditures $m$ independently. Utility falls as the price of the good rises and as the total amount of pollution in the environment increases. Since firms are symmetric, we let $d=f(Z, q)$ be the total environmental degradation caused by an individual firm, and $D=D\left(N^{f}, Z, q\right)$ be the total amount of degradation. Recognizing that $q^{*}$ is 
chosen by firms in stage 3 and that the number of firms is fixed, we suppress the dependence of $D$ on $q$ and $N^{f}$, and the total welfare of a consumer is then

$$
U^{N}(P(Z), D(Z))-m
$$

A consumer's optimal choice of $m$ is given by the following equation:

$$
\left[U_{P}^{N} P_{Z}+U_{D}^{N} D_{Z}\right] Z_{m}=1
$$

Using the shorthand notation $U^{N}(Z)=U^{N}(P(Z), D(Z)),(6)$ can be simplified to $U_{Z}^{N} Z_{m}=1$. We assume $U_{\mathrm{zz}}^{N}<0$; note that $U_{Z}^{N}$ is initially positive, but declines and so can become negative.

Equations (4) and (6) generate reaction functions $l^{*}\left(m, Z^{V}\right)$ and $m^{*}\left(l, Z^{V}\right)$ for firms and consumers, respectively, in the influence game. We shall assume that $Z_{\mathrm{ML}} \approx 0$, which ensures that the reaction functions are upward sloping, as illustrated in Figure 2, indicating that lobbying expenditures are strategic complements. We also assume regulation never mandates an increase in pollution; as a result, firms will curtail their expenditures on influence when $Z^{M}(M, L)$ reaches zero. This effect is shown in the figure for the case where firm and consumer pressure is equally effective: firms' reaction curves are the upper envelope of the 45-degree line and the $l^{*}\left(m, Z^{v}\right)$ function that would apply if regulations could force firms to become dirtier. Equilibrium levels of pressure are $l^{e}\left(Z^{V}\right) \equiv l^{*}\left(m^{e}, Z^{V}\right)$ and $m^{e}\left(Z^{V}\right) \equiv m^{*}\left(l^{e}, Z^{V}\right)$.

\section{Stage 1: Voluntary Pollution Control}

Prior to the interest group rivalry process that generates pollution-control policy, firms can choose a level (possibly zero) of voluntary pollution control. Let $Z\left(Z^{V}\right) \equiv Z^{V}+Z^{M}\left(Z^{V}\right)$ and assume that $Z(0)>0$, which avoids the uninteresting case in which the external costs of pollution to consumers are too small to generate any legislative requirements for pollution control. Firms thus choose $Z^{\gamma}$ to maximize the following equilibrium profit function: 


$$
\pi^{I}\left(Z^{V}\right)=\pi^{N}\left(Z\left(Z^{V}\right)\right)-l^{e}\left(Z^{V}\right)
$$

where the superscript I indicates that profits are measured net of influence costs. We also denote consumer utility, net of influence costs, by $U^{I}\left(Z^{V}\right)=U^{N}\left(Z\left(Z^{V}\right)\right)-m^{e}\left(Z^{V}\right)$.

A crucial effect of voluntary abatement is to change the outcome of the influence game. It is straightforward to establish how the players' reaction curves shift as $Z^{V}$ rises. Totally differentiating (4) and

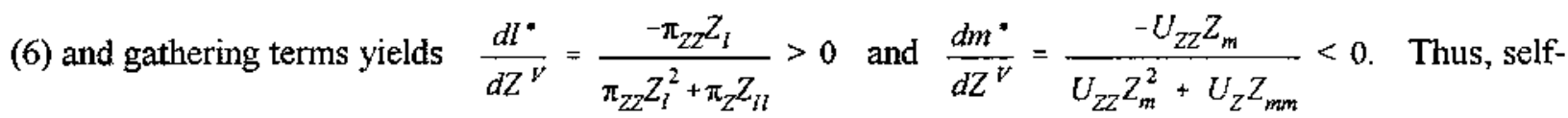
regulation makes the firms "tough" in the influence game while also making consumers "soft."24 Figure 2 illustrates the shifts in consumer and firm reaction functions in response to an increase in voluntary abatement. Functions superscripted with a 0 represent reaction functions when the level of voluntary abatement is zero, while those represented with a + superscript are reaction functions resulting from a positive level of voluntary abatement. With positive voluntary abatement, a consumer's reaction function shifts downward, reflecting a reduced marginal value of further emissions control. At the same time, a firm's reaction function shifts outward, reflecting a higher marginal cost of further control. Note, however, that the lower portion of the firm's reaction curve does not shift. This reflects the constraint that firms are not allowed to become "dirtier," so they just match consumer expenditures on influence once the level of mandatory abatement falls to zero.

\section{CONDUCT OF FIRMS AND CONSUMERS}

In this section, we analyze the behavior of firms and consumers in the model presented above. We are particularly interested in the question of when preemption via voluntary abatement is profitable. U.S. antitrust law makes illegal all collusive attempts to restrict sales quantity or raise price. To the best of our knowledge, however, these laws do not preclude firms from cooperating to increase their levels of voluntary pollution abatement. ${ }^{25}$ In fact, firms often use trade associations to self-regulate via uniform product and 
production standards; for example, a recent survey of firms that emit toxic pollutants found that companies were more likely to participate in pollution programs sponsored by the firm's trade association. ${ }^{26}$ Proposition I establishes conditions under which firms' profits can be enhanced by cooperative voluntary pollution abatement that preempts mandatory controls. ${ }^{27}$

Proposition 1: There exists a range of consumer fixed costs of organizing on which a perfectly collusive oligopoly chooses a positive level of voluntary abatement and thereby preempts consumer intervention in the regulatory process. Let $\left[f_{Z_{\max }^{v}}, f_{\text {blockade }}\right]$ be this range. Then $f_{Z_{\max }^{v}} \geq 0$, and for $f_{Z_{\max }^{v}}<f\left(N^{c}\right)<f_{\text {blockade }}$ the firm's choice of $Z^{\nu}$ is decreasing in $f\left(N^{c}\right)$; for $f\left(N^{c}\right)>f_{\text {blockade }}$ consumer intervention is "blockaded," i.e. preempted with $Z^{V}=0$.

The basic intuition of the proposition is simple: political costs drive a wedge between the consumer utility of voluntary abatement and mandatory abatement, and firms can take advantage of this wedge to prempt regulation. The relationship between the industry's optimal choice of $Z^{V}$ and the level of fixed costs faced by consumers is illustrated in Figures $3 \mathrm{~A}$ and $3 \mathrm{~B} . \quad Z_{\max }^{V}$ is the maximum voluntary abatement level for which successful preemption is more profitable than choosing $Z^{V}=0$ and fighting the influence game. There is a corresponding level of consumer fixed costs such that $Z_{\max }^{V}$ is just sufficient to preempt; we denote this level by $f_{Z_{\max }^{V}}$. For organizing costs above $f_{Z_{\max }^{V}}$, preemption is always profitable, and the requisite level of voluntary abatement declines with $f$. Of course, if fixed costs are large enough, i.e. $f \geq f_{\text {blockade, }}$ consumers will decide not to lobby even if $Z^{\prime}=0$; in this case we say that entry is blockaded. 
Whether $f_{Z_{\max }^{v}}>0$ is ambiguous in general. The two parts of Figure 3 represent two possible patterns for low levels of consumer fixed organizing costs. ${ }^{28}$ In Figure $3 \mathrm{~A}$, the bold line depicts voluntary abatement for the case when $f_{Z_{\max }^{v}} \leq 0$, in which case the level of voluntary abatement declines monotonically from the level it takes on when $f\left(N^{C}\right)=0$. In Figure 3B, $f_{Z_{\max }}>0$, so it is unprofitable to preempt when consumer fixed costs are zero; in this case the bold line shows that no voluntary abatement is observed unless $f \geq f_{Z_{\max }^{V}}$. In this latter case, there is a sharp drop in voluntary abatement if consumer fixed costs fall below $f_{Z_{\max }^{v}}$.

It is important to emphasize that, in general, consumer fixed costs are not necessary for preemption to occur. Whether preemption is profitable at $f\left(N^{c}\right)=0$ (and hence which of the foregoing cases applies) depends on the magnitude of equilibrium consumer influence costs $m^{e}\left(Z^{v}\right)$ : if these are high enough then preemption can be profitable even if consumers' fixed organizing costs are zero. These influence costs, in turn, depend on the curvature of the profit and utility functions. Consumer expenditures on influence tend to be high when $U_{Z}$ is large and/or $U_{z z}$ is small, since then the marginal consumer benefit of further abatement is high and declines slowly. Consumer lobbying costs also tend to be high when $\pi_{\mathrm{z}}$ and/or $\pi_{\mathrm{zz}}$ is large, since in this case abatement rapidly becomes very costly to the firms, and they will fight hard to avoid mandatory abatement. In any event, as long as organizing costs are above $f_{Z_{\max }^{v}}$, voluntary abatement declines with $f$.

While firms may be able to preempt collusively, it is not obvious that preemption is possible when firms must select voluntary abatement levels noncooperatively. The following proposition addresses this issue. While a continuum of asymmetric preemption equilibria exist, we choose to focus on symmetric equilibria for simplicity and clarity. 
Proposition 2: Symmetric preemption by a noncooperative oligopoly is possible for

$$
f\left(N^{c}\right) \in\left[f_{Z_{N C}^{V}}, f_{\text {blockede }}\right] \text {, where } f_{Z_{N c}^{v}}>f_{Z_{\max }^{v}} \text {. }
$$

When the firms cannot coordinate on voluntary abatement, free-riding occurs. At the collusive level of voluntary abatement, any given firm prefers to eschew voluntary abatement and allow the influence game to occur. By so doing, it enjoys at no cost the reduced level of mandatory abatement made possible by its rivals' voluntary abatement activities. In addition, it gains a cost advantage relative to its rivals because it does not undertake the (costly) voluntary action. As a result, the collusive level of voluntary abatement cannot be sustained as a non-cooperative equilibrium. Nevertheless, the threat of mandatory abatement in the second stage of the game will still support an equilibrium with some degree of non-cooperative preemption. The key point is that for small enough voluntary abatement levels, firm $i$ is willing to match or exceed the levels undertaken by the other firms, since its action is pivotal to preempting regulation. Thus preemption will still occur for large consumer fixed costs, but there are some lower levels of $f\left(N^{c}\right)$ for which preemption would have occurred collusively but not non-cooperatively, i.e. $f_{Z_{N C}^{v}}>f_{Z_{\max }^{v}}$.

Our results in Proposition 2 contrast sharply with those of Gilbert and Vives (1986) and Donnenfeld and Weber (1995), who find that oligopolies have incentives to provide excessive levels of output or quality when engaging in entry deterrence. The key difference is that in those models, firms derive private benefits from contributing to the "public good" of entry deterrence, while in our model contributions carry private costs but not private benefits.

One might think that as the number of firms, $N^{f}$, increases, growing free-rider problems would make preemption more difficult. In our model, however, whether preemption occurs depends upon two factors: 1) the firms' ability to coordinate sufficient voluntary abatement ("supply"), and 2) the level of voluntary abatement required to preempt consumer entry into the political process ("demand"). The "supply" of preemption falls with $N^{\prime}$, since free-rider problems plainly worsen. The "demand" for preemption, however, 
depends on the mandatory abatement level determined in the influence game, which is a function of aggregate lobbying activity, and may either rise or fall with the number of firms. With respect to the firms' pressure activities, for example, Peltzman (1976) shows that firms' aggregate influence rises and eventually falls as the number of firms grows, but one cannot predict in general whether an additional group member strengthens or weakens the group's ability to apply political pressure. Thus, there is no theoretical presumption that voluntary abatement is more likely in industries with only a handful of producers. Interestingly, the empirical work of Arora and Cason (1995) finds that voluntary abatement is actually more likely to occur in unconcentrated industries.

To sum up, the results of this section identify conditions under which firms can profitably preempt, taking advantage of the wedge that lobbying and organization costs drive between voluntary and mandatory abatement. Lobbying costs alone may not be enough to support preemption, and thus a strictly positive level of fixed organizing costs may be required for preemption to be profitable. In either case, once preemption becomes profitable, the equilibrium level of voluntary abatement declines monotonically with consumer organizing costs. The threshold level of consumer organizing costs at which preemption becomes profitable is higher when firms act non-cooperatively than when they coordinate on voluntary abatement.

\section{WELFARE IMPLICATIONS}

In this section, we assess welfare from two perspectives. First, we establish a benchmark for the socially optimal amount of pollution control and compare it against the outcome of the influence game; we then examine whether self-regulation results in a move toward the social optimum. Second, we examine the more limited, but perhaps more important, question of whether voluntary pollution control Pareto-dominates the outcome of the influence process when there is no voluntary abatement.

A welfare maximizing social regulator would choose $\mathrm{Z}$ to maximize 
yielding

$$
\frac{\pi_{Z}^{N}}{U_{z}}=-\frac{N^{c}}{N^{f}} .
$$

On the other hand, equations (4) and (6) imply that the equilibrium of the influence game is characterized by $^{29}$

$$
\frac{\pi_{Z}^{N}}{U_{Z}}=\frac{Z_{m}}{Z_{l}}
$$

The social optimum, given by (9), differs in two ways from the equilibrium of the influence game. First, the welfare maximum weights firms and consumers equally. As a result, equation (9) does not include the relative impact of lobbying expenditures, unlike the equilibrium result shown in (10). Because the effectiveness of lobbying is subject to diminishing returns, the group that spends more on lobbying will be worse off in the influence game than in the welfare maximum. Second, the welfare maximum reflects the relative number of firms and consumers (as can be seen in the right-hand side of (9)), but the equilibrium result does not. ${ }^{30}$ The reason for the second difference is that the influence game reflects our assumption that all players make their influence decisions non-cooperatively. Thus, each consumer or firm equates the last dollar of lobbying expenditures to his own individual marginal benefit from a change in the level of abatement. The effects of that marginal expenditure on other parties are ignored, however, so free-rider effects distort the equilibrium away from the welfare maximum. Free-rider problems increase with the number of members in an interest group, so relative to the welfare maximum, the influence game is biased toward the group with the smaller number of members.

It is important to note that both effects—diminishing returns to lobbying and free-rider problemswork against consumer interests. We focus on the case where without voluntary abatement consumer 
involvement leads to some pollution regulation, i.e. consumers in the aggregate devote more resources to lobbying than do firms. Because of diminishing returns to lobbying, the influence game is worse for consumers than is the welfare maximum. In addition, we assume there are more consumers than firms, so consumers face worse free-rider problems, further reducing consumer welfare in the influence game. We state the foregoing observations as Proposition $3 .^{31}$

Proposition 3: If an industry has more consumers than firms, and will in equilibrium face some regulatory requirements for pollution control, the political influence game generates less abatement than is socially optimal.

It is indeterminate in general whether self-regulation moves the level of pollution control closer to the socially optimal level. Proposition 1 guarantees the existence of a preemptive level of abatement if $f\left(N^{c}\right)$ is large enough. As $f\left(N^{c}\right)$ tends toward $f$ blockad, this preemptive level goes to zero, and consequently will be lower than the total abatement that would result from the influence game alone. Conversely, when $f\left(N^{c}\right)$ is low, firms may self-regulate to a level beyond what would result from the influence game in order to economize on lobbying costs.

A more meaningful question, however, is whether voluntary abatement improves welfare beyond what it would have been with no voluntary abatement. In order to address this question, we first establish a lemma that will provide a sufficient condition for the welfare effects of self-regulation to be positive. The key requirement is that positive or negative "complementaries" between the influence inputs of the two groups (as measured by the magnitude of $Z_{m l}$ ) are not too great. As Becker (1983, p. 376) points out, there is no a priori rationale for either a positive or negative sign on these complementarities, and we take no position as to their sign, simply considering limits on their magnitude. 
Lemma: There exists $\varepsilon>0$ such that if $\left|Z_{m l}\right|<\varepsilon \forall(m, l)$, then as $Z^{V}$ increases, $Z\left(Z^{V}\right)$ rises, $m^{e}\left(Z^{V}\right)$ falls, and $l^{e}\left(Z^{Y}\right)$ rises.

As we noted in section II, voluntary abatement shifts the reaction curves of consumers and firms in the influence game, making consumers "soft" and firms "tough." The lemma provides a simple sufficient condition under which the direct effects of voluntary abatement on each interest group's lobbying expenditures (holding the rival's expenditures constant) are greater than the strategic effects (mediated through a change in the rival's expenditures). When the conditions of the Lemma hold, it is straightforward to show that voluntary abatement raises consumer welfare, relative to the case where firms undertake no voluntary abatement.

Proposition 4: If preemption occurs, and the conditions of the Lemma hold, then both consumer welfare and profits are increased, relative to their levels were government regulation imposed in the absence of voluntary abatement.

If the industry chooses to preempt, then preemption must be profitable. It is less obvious that consumers are better off; it is not enough simply to show that consumers are better off at $Z=Z^{V}$ than at $Z=$ 0 . It is necessary to establish that consumers are better off than they would have been if no voluntary abatement had taken place and they had lobbied for standards $Z(0)$ that might have been stricter than $Z^{\nu}$. The argument proceeds in two steps. First, observe that as long as consumers enter the influence game, they are always better off when firms have engaged in voluntary abatement. This is so because total abatement increases with $Z^{V}$ and consumers' lobbying expenditures decrease with $Z^{V}$, as shown in the Lemma. Together the two effects must raise consumer welfare. Second, observe that if the firm preempts, it chooses a voluntary abatement level $Z^{V}$ such that consumers are just indifferent between entering the influence game to obtain $Z\left(Z^{V}\right)$, and avoiding the influence game altogether. However, the preceding point shows that 
consumers prefer the influence game with $Z^{v}>0$ to the influence game with $Z^{v}=0$. Thus, if consumers allow themselves to be preempted by some $Z^{v}>0$, they must be better off than they would have been had they fought to impose standards on an industry with no voluntary abatement.

Proposition 4 has two main policy implications. First, it supports allowing industry to coordinate on a choice of pollution limits, as long as the strategic effects of self-regulation on consumers' lobbying effectiveness is not too great. As Proposition 2 indicates, in some situations firms acting non-cooperatively will choose not to engage in voluntary abatement, but would do so if they could coordinate their actions. Proposition 4 shows that welfare would be enhanced by such coordination, as long as $Z_{m l}$ is not too large. In this context, antitrust prosecution of "collusion" will reduce welfare. It is worth noting that as part of the 33/50 Program, the EPA has convened several conferences on voluntary abatement that "promoted collaborative action and partnerships among the conference participants." ${ }^{32}$

Previous work suggests that cooperative pollution-control activity by industry does not always have a benign effect. For example, Hackett (1995) finds that R\&D by industry members to reduce the cost of more stringent pollution-abatement technology may be motivated by the opportunity for successful innovating firms to lobby for more stringent industrial regulation and thus raise their rivals' costs. Anticipating this, industry members can organize a pollution-control research joint venture to slow the pace of innovation in lower-cost pollution abatement technology. In fact, as discussed in detail by Bittlingmayer (1987), the Department of Justice successfully prosecuted a consent decree with the Automobile Manufacturer's Association for using a research joint venture formed in the 1950's to slow the adoption of more stringent pollution-control devices on automobiles. Appropriate antitrust treatment must be sophisticated if it is to distinguish between these different motivations for cooperative pollution-control activities by industry.

A second implication of our analysis is that government should not necessarily subsidize consumer involvement in the regulatory process. State regulatory agencies have increasingly taken to funding 
branches with names like "Division of Ratepayer Advocates" or "Office of Consumer Counsel" to intervene in utility rate cases. These actions appear designed to offset the high costs to consumers of intervening in the regulatory process, and indeed our analysis shows that such subsidies can shift the policy regime from one of no government regulation (because consumer organizing costs are too high) to one of preemption. Our results, however, also indicate that these efforts may unintentionally make consumers worse off by substituting government regulation for less costly industry self-regulation. The fixed cost of organizing implicitly commits consumers to an "acceptable" level of self-regulation beyond which they will not enter the political process. If organizing costs fall too low, this commitment may be eroded and firms may find preemption unprofitable; by Proposition 4 this may make consumers worse off.

Our analysis also identifies a linkage between the effects of antitrust and regulatory policy. Granting industry the right to collude on pollution control lowers the threshold of consumer organizing costs below which self-regulation becomes unprofitable. Thus, for any given $f\left(N^{c}\right)$, antitrust policy allowing such cooperation reduces the danger that regulatory subsidization of consumer political action will undermine self-regulation.

\section{TOXIC CHEMICAL RELEASES AND THE THREAT OF REGULATION}

In the preceding sections, we have presented a theoretical model of self-regulation and used it to assess the welfare consequences of such voluntary corporate actions. In this section, we test empirically the main positive implication of the model, namely that firms engage in more self-regulation when they perceive a greater threat of government regulation. To do so, we use what is to our knowledge the only existing dataset on corporate self-regulation, namely the Environmental Protection Agency's Toxic Release Inventory (TRI), which is described in more detail below. We use the TRI data on toxic chemical releases to see if firms engage in more voluntary pollution abatement in states that pose a greater threat of regulation. ${ }^{33}$ 
Our goal is to explain changes in the rate of toxic emissions over time, controlling for the underlying economic activity that generates these emissions. Toxic chemicals are of special interest because of their potentially important health impacts, recent improvements in the availability of public data on toxic releases, and the threat of both federal and state regulation. Starting in 1987, the Environmental Protection Agency (EPA) stepped up its collection of toxics data as a result of Title III of the Superfund Amendments and Reauthorization Act (SARA) of 1986, also known as the Emergency Planning and Community Right-toKnow Act (EPCRA). This law mandates that companies report releases of over 400 different toxic chemicals, many of which are otherwise unregulated. It applies to all manufacturing facilities that have 10 or more employees and that manufacture or process more than 25,000 pounds or use more than 10,000 pounds of any of the reportable chemicals. The EPA makes this information available to the public through the Toxic Release Inventory (TRI). The first year for which data are available is 1987; this information was released to the public in June of 1989.

Our theory, of course, predicts that the release of the TRI would in itself significantly lower the information costs faced by consumer and environmental groups, thereby increasing the threat of regulation faced by firms and increasing the incentives for self-regulation. In fact, there have been massive cuts in emissions since 1987 , ranging from $38 \%$ to $51 \%$ for different classes of chemicals, ${ }^{34}$ although it is impossible to determine the role of the TRI in stimulating these reductions since data were not available before its release. Hamilton (1995) did find that the stock value of firms reporting TRI releases fell by $\$ 4.1$ million on the day the pollution data were first released. Furthermore, Konar and Cohen (1997) found that firms that faced the largest stock price decline upon the initial release of the TRI to the public subsequently reduced their emissions more than their industry peers. These findings are consistent with the notion that the TRI reduced information costs and increased the threat of regulation, although the authors of these papers do not attempt to establish the chain of causation that links stock value to environmental performance. 
Our empirical analysis focuses on reductions over the period 1988-1992 in total toxicity-weighted releases of 17 key toxic chemicals per PPI-deflated dollar value of shipments. ${ }^{35}$ Emissions of the toxic chemicals we study are currently legal, but these chemicals have been identified by the Environmental Protection Agency as "high priority" chemicals. These chemicals are listed in Table 1, along with information on their relative toxicities. Some but not all of the chemicals have been identified as potential carcinogens, so in order to standardize our risk measure across chemicals we have focused on non-cancer risks from inhalation and ingestion. ${ }^{36}$

To control for the important link between production and pollution we collected data on the value of shipments for the seven two-digit manufacturing industries responsible for over $70 \%$ of the releases of our 17 toxic chemicals. These industries are Chemicals (SIC Code 28), Petroleum Refining (29), Rubber and Plastics (30), Primary Metals (33), Fabricated Metals (34), Electrical Equipment (36), and Transportation Equipment (37). We deflated the dollar value of shipments for each industry by the industry-specific producer price index generated by the Bureau of Labor Statistics. The shipments data and other data we use are summarized in Table 2 .

We include a number of variables expected to shift the marginal benefits and costs of abatement, and to affect consumer information and organizing costs. Our independent variables can be broken into six major categories: 1) Geographic/climatic data, 2) Socioeconomic data, 3) Industry characteristics, 4) General business climate, 5) Legal climate, and 6) State attitudes toward the environment.

We include three control variables that characterize the geographic and climatic situation in each state: water area, mean elevation, and average July temperature; we also include land area indirectly through a variable measuring population density per square mile. We have no strong prior hypotheses regarding the effects of the first three variables, but include them because they may cause states to vary in their vulnerability to emissions of pollutants. ${ }^{37}$ For example, states with large surface water areas may face greater health threats from water-borne toxic emissions, but alternatively they might also be able to absorb 
greater levels of toxic emissions without health dangers; hence we simply include the variable as a control. With regard to population density, however, we do have a clear hypothesis: we expect that the pressure to reduce toxic emissions is greater in densely populated states, since the potential harm from toxic emissions is higher there.

We include a number of socioeconomic variables in addition to population density. We use per capita income and educational attainment (percentage of residents with college degrees or higher), expecting both of these variables to increase the demand for pollution abatement. In addition, we collected data on the number of members in the Sierra Club and the Natural Resources Defense Council per capita in each state. Higher levels of this variable are expected to increase the pressure for pollution abatement, since environmental group members presumably place high marginal values on abatement, in addition to having an existing organizational structure that lowers the fixed costs of organizing to press for toxics regulation. We also construct an interaction term equal to the product of the state's initial emissions/shipment level in 1988 and its environmental group membership per capita. Our expectation is that initially dirty states with high environmental-group membership will face strong political pressures to reduce emissions.

Several variables capturing industry characteristics in each state are included. We include the real value of manufacturing shipments from our seven key industries as a control variable, but without a clear sign prediction. On one hand, high shipments indicate an industry that may have considerable political power that it can use to resist regulatory threats. On the other hand, high shipments may mean that industry is viewed as having "deep pockets" that can be tapped through additional regulatory requirements or through lawsuits, or just that industry can better afford investments in voluntary pollution abatement. Another included variable is the number of plants emitting our 17 key toxic chemicals, as a measure of the coordination problem facing industry in a given state. While we also gathered data on the number of firms emitting these chemicals, the two measures have a correlation coefficient of $98.4 \%$, so we decided not to include both measures. Since coordination issues within a firm presumably increase with the number of 
plants the firm operates, we chose to use the former measure. We also include as an independent variable the toxicity-weighted emissions in each state in 1988. Assuming the marginal cost of abatement is increasing, currently dirty states should have relatively low marginal costs of abatement, so these states should find emissions reduction easier than do other states.

The variables described thus far provide a set of "shifters" that strengthen or weaken the latent political pressure for corporations to self-regulate. Each of these variables affects either the marginal benefits of abatement to state residents, the marginal costs of abatement to firms, or the information and organization costs faced by state residents who wish to pressure corporations to reduce their toxic emissions. If these variables prove significant, this supports our thesis that the threat of interest-group action can drive firms to self-regulate. It is also of interest, however, to understand exactly how these interest-group pressures are transmitted to firms. States differ substantially in terms of their overall business climate, the legal precedents they operate under, and their propensity to pass environmental regulations. The next three sets of variables we introduce attempt to capture these three types of state characteristics, so as to gain insight into the mechanisms through which latent political pressure is transmitted. For example, environmentalists may impose new state regulations on toxic emissions, or they may sue a company for liability under the federal Comprehensive Environmental Response, Compensation and Liability Act ("CERCLA"), under state versions of CERCLA, or under common law. ${ }^{38}$

To characterize a state's overall business climate, we follow Holmes (1998) and use the presence or absence of a "right-to-work" law as indicative of how favorable a state is as a business location. ${ }^{39} \mathrm{We}$ expect pro-business states (those with a right-to-work law) to pose less of a threat of government regulation and hence to observe less corporate self-regulation.

A state's legal climate is characterized here by two variables. First, we use 1990 Census data on the number of lawyers per capita as a measure of the overall threat of litigation in a given state. Second, we include a dummy variable indicating whether a state has a law imposing strict liability in toxic waste 
cleanup cases. ${ }^{40}$ By creating legal precedents requiring polluters to bear pollution damages, such laws encourage legal action against polluters and should encourage firms to handle toxic substances with greater care. If either of these variables is significant in the regressions to follow, this supports the hypothesis that at least a portion of interest-group pressure is transmitted through the threat of litigation, not just through the threat of direct regulation.

We also include four measures of a state's political climate with specific reference to environmental issues: 1) the League of Conservation Voters (LCV) rating for the state's Congressional delegation over the period 1985-1990, 2) a composite index of state policy initiatives compiled by the Institute for Southern Studies, 3) a measure of state and local funds spent on air quality management in fiscal 1988, and 4) a variable indicating whether a state had a law as of 1991 promoting cuts in toxic chemical production at its source (even though these laws do not require facility plans or detailed reporting) ${ }^{41}$ Each of these variables provides additional insight into a given state's propensity to support measures protecting the environment.

Inspection of the data reveals Montana to be a clear outlier, with far higher emissions per unit of shipments in 1988 than any other state. Even more strikingly, Montana shows a sharp increase in emissions per unit shipments over time that is unique among the fifty states. Recall that our theoretical analysis shows consumers may effectively be blockaded from the political process when their costs of producing political pressure are too high. The data suggest that Montana is such a state, apparently immune from the pressures present in the rest of the U.S. Given these concerns, we include a dummy variable for Montana to account for its unique status.

Our regression analyses of toxic releases per value of shipments are presented in Table 3 . The first estimation includes all the variables discussed above. It explains $98 \%$ of the variation in toxic reductions across states. Heteroscedasticity is controlled for by using White-corrected standard errors. Although many of the variables in the regression are not statistically significant, several provide insight into the forces behind voluntary abatement of toxic emissions. Two of the geographic/climatic variables 
prove significant. States with greater water areas reduced toxic emissions less rapidly over time, as did states with higher average July temperatures.

Turning to the socioeconomic variables, we find that higher population density is associated with greater voluntary abatement, although the relationship is not statistically significant. Similarly, high-income states saw greater abatement, but again the relationship was statistically insignificant. In fact, only one of the socioeconomic variables proved significant, namely the interaction between initial emissions level and environmental group membership. Its coefficient is negative and significant at the $.005 \%$ level. As expected, initially dirty states with large environmental memberships experience substantial pressure to reduce emissions. This provides strong evidence that the political salience of initial emissions levels depends critically on the strength of state environmental group membership.

Two variables indicating industry characteristics produced interesting results. States with a greater number of plants in our seven selected industries engaged in significantly less abatement, consistent with the hypothesis that coordination and free-rider problems become worse as the number of facilities to be coordinated rises. In addition, states with a higher level of manufacturing shipments—controlling for the number of plants—reduced emissions faster. This suggests that states where firms have "deep pockets" face a greater threat of more stringent policies toward toxic emissions or are simply better able to afford abatement.

To a substantial extent, the structural variables that shift the costs and benefits of self-regulation enter the regression as expected, supporting our basic model of preemptive self-regulation. Our attempt to determine the precise pathways through which political pressure is exerted fared less well. Our measure of overall business climate has a positive coefficient, indicating that states with probusiness attitudes (as proxied by the presence of a right-to-work law) saw less voluntary pollution abatement. The result was not statistically significant, however. Neither of our measures of legal climate were significant, nor were the measures of state policies toward the environment. 
We have a small sample, and some of our explanatory variables are highly correlated with one another. It is thus possible that some economically significant variables are imprecisely estimated in regression (1) and appear statistically insignificant. Hence, we present in estimation (2) the results of sequentially eliminating the least significant independent variables in each category of explanatory variables. The results are largely unchanged from those in estimation (1). One difference is that the number of environmental group members per capita becomes significant. Note that two steps are needed to interpret the effect of environmental group membership when both this term and the interaction term are taken into account, since the marginal effect of more environmental group members enters the regression through both terms. Using estimation (2), we see that the marginal impact on abatement of an increase in membership is now equal to $(12.0738-.2847 *$ Tox/Value 1988). The sample mean of toxic releases/value in 1988 was 151.647 pounds of toxicity-weighted chemicals per thousand dollars of shipments. Evaluated at this level, an increase in state environmental group membership of 1 member per thousand state residents reduced the level of toxic emissions by 31.1 toxicity-weighted pounds per thousand dollars of shipments. ${ }^{42}$

Overall, then, we identify three main factors that explain toxic reductions over time. First, and most important, is the presence of strong environmental group membership in a state with high emissions levels. In this situation, firms have relatively low marginal abatement costs, consumers value abatement highly, and consumer organizing costs are low. The threat of mandatory regulation is high while the cost of self-regulation is low, so it makes good political-economic sense for firms to engage in voluntary emissions reductions. Second, states with a smaller number of plants enjoy greater levels of voluntary emissions reduction; in these states, firms are better able to overcome free-rider problems. Third, states with higher values of manufacturing shipments enjoy greater voluntary abatement.

Our results indicate that latent political pressure does indeed encourage firms to undertake voluntary self-regulating actions, and that firms are more responsive to such pressures when the costs of coordination 
are low. We are unable to shed much light on the precise mechanisms by which pressure is transmitted, however. All of the measures of state political climate-including measures of overall business climate, legal climate and the state's propensity for environmental regulation-were statistically insignificant. Given the complex nature of the political environment, and the limited power of a pure cross-sectional analysis of the fifty states, this is perhaps not surprising. Future research exploring exactly how environmental groups create political threats would be a valuable contribution.

\section{CONCLUSIONS AND EXTENSIONS}

We have developed a model in which firms can use self-regulation to preempt government-imposed regulations. When it is costly for consumers to organize and to influence the political process, firms can match the net utility consumers expect from regulatory controls with a lower level of voluntary controls, and can thereby deter consumer groups from mobilizing to enter the political process. As the threat of regulation grows, e.g. because of reductions in consumers' informational and organizational costs, self-regulation becomes more stringent. Furthermore, our theory shows that firms cannot use self-regulation to undermine consumers' threat of imposing mandatory regulations; as a result, when self-regulation preempts government action, both firms and consumers are better off.

Evidence on recent reductions in toxic chemical emissions is consistent with the positive predictions of our thesis. When Congress reauthorized Superfund in 1986, Title III of the legislation required companies to report their emissions of over 300 toxic chemicals, thereby dramatically lowering consumer information costs. In our framework, after this data began to be collected total releases of toxic chemicals should have dropped significantly. This hypothesis cannot be tested directly, since the data were not collected prior to the passage of the law, but the massive cuts in emissions since 1987 (ranging from $38 \%$ to $51 \%$ for different classes of chemicals) are certainly consistent with our model's predictions. Furthermore, the EPA's voluntary 33/50 Program, initiated in 1991, may have signalled a greater threat of federal 
regulation for the 17 chemicals it encompasses (which are also the ones we examine here); emissions of these 17 chemicals fell $42 \%$ from 1991 to 1994 , while emissions of the other TRI chemicals fell by $22 \%$, further suggesting that the threat of regulation matters. Finally, we use the new data on toxic releases to examine how state-level variation in the threat of regulation affects incentives for voluntary abatement. Our most striking finding is that states with high initial emissions levels along with strong environmental group membership generate more voluntary pollution abatement. In these states, firms have relatively low marginal abatement costs, and face consumers who highly value marginal improvements in environmental quality and are already well-organized to apply political pressure. The cost of selfregulation is low while the threat of government regulation is high, so voluntary abatement is a sound business decision.

There are many potentially interesting extensions of our model. For example, if firms sink investment in a technology with an upper limit on pollution control capability, then they must scrap that technology and adopt a new one if standards exceed the current technology's limit. Stiffer standards would thus be highly costly, and preemption would be more likely when such a technology is used. Allowing for asymmetric firms and for voting behavior would also be interesting extensions of the model, as would research on whether alternative forms of threatened regulations are equally attractive targets for preemption. For example, a threatened pollution tax might elicit more voluntary abatement than a threatened system of tradeable permits, especially if the latter involved grandfathering provisions protecting existing firms.

Another promising direction is a marriage of our interest-group model with a vertical product differentiation model, in which voluntary abatement attracts customers willing to pay a premium for environmentally friendly products. Lutz, Lyon and Maxwell (forthcoming) study a vertical differentiation model with minimum quality standards set by a welfare-maximizing regulator. Combining their framework with our political economic analysis should allow for a rich set of results. 


\section{APPENDIX}

Proof of Lemma: Note first that

$$
\frac{d m^{e}}{d Z^{v}}=\frac{\frac{\partial m^{*} \frac{\partial l^{*}}{\partial l} \frac{\partial Z^{V}}{\partial Z^{*}}+\frac{\partial m^{*}}{\partial Z^{V}}}{1-\frac{\partial m^{*}}{\partial l} \frac{\partial l *}{\partial m}}}{\text {. }}
$$

and similarly that

$$
\frac{d l^{e}}{d Z^{V}}=\frac{\frac{\partial l^{*}}{\partial m} \frac{\partial m^{*}}{\partial Z^{v}}+\frac{\partial l^{*}}{\partial Z^{V}}}{1-\frac{\partial l^{*}}{\partial m} \frac{\partial m *}{\partial l}}
$$

These expressions show that the equilibrium change in lobbying levels as a function of $Z^{V}$ depends on both the shift in the player's own reaction curve as well as the movement along his reaction curve caused by the shift in the rival's reaction curve. Letting $\lambda \equiv 1-\left(\partial m^{*} / \partial l\right)\left(\partial l^{*} / \partial m\right)$, we note that $\lambda>0$ because the reaction curves are assumed to be stable. We can now write $d m^{e} / d Z^{V}=(\theta / \lambda)\left(d Z / d Z^{V}\right)$ and

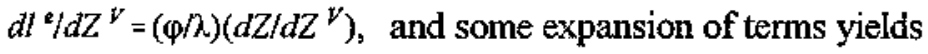

and

$$
\theta=\frac{U_{m I}^{I}}{U_{m m}^{I}} \frac{\pi_{z z} Z_{I}}{\pi_{l I}^{I}}-\frac{U_{z Z}^{I} Z_{m}}{U_{m m}^{I}}
$$

$$
\varphi=\frac{\pi_{l m}^{I}}{\pi_{l l}^{I}} \frac{U_{z z}^{I} Z_{m}}{U_{m m}^{I}}-\frac{\pi_{z z}^{I} Z_{l}}{\pi_{l l}^{I}} .
$$

Now we can write $d Z / d Z^{V}=1+d Z^{W} / d Z^{V}=1+Z_{m}\left(d m^{e} / d Z^{V}\right)+Z_{l}\left(d l e / d Z^{V}\right)=I+Z_{m}(\theta / \lambda) d Z / d Z^{V}+Z_{l}(\varphi / \lambda)$ $d Z / d Z^{V}$. Rearranging terms yields $d Z / d Z^{V}=1 /\left(I-Z_{m} \theta / \lambda-Z_{l} \varphi / \lambda\right)$. Thus, sufficient conditions for $d Z / d Z^{V}$ $>0$ are $\theta<0$ and $\varphi>0$.

Next, note that $U_{m l}^{I}=U_{z Z}^{f} Z_{m} Z_{l}+U_{Z} Z_{m b}$ and if $Z_{m l}=0$ then $U_{m l}^{f}=U_{Z Z}^{f} Z_{m} Z_{l}$. Substituting this into the expression for $\theta$, and noting that $\pi_{l l}^{l}=\pi_{z Z}^{\prime}\left(Z_{l}\right)^{2}+\pi_{Z}^{I} Z_{t l}$, we obtain: 


$$
\theta=\frac{-U_{Z z}^{\prime} Z_{m}}{U_{m m}^{I}} \frac{\pi_{z} Z_{l l}}{\pi_{l l}^{I}}<0
$$

Similar reasoning yields

$$
\varphi=\frac{-\pi_{z z}^{I} Z_{l}}{\pi_{l l}^{I}} \frac{U_{z}^{I} Z_{m m}}{U_{m m}^{I}}>0
$$

Hence $d Z / d Z^{V}>0$. Furthermore, $d m^{e} / d Z^{V}=(\theta / \lambda)\left(d Z / d Z^{V}\right)<0$ and $d l^{e} / d Z^{V}=(\varphi / \lambda)\left(d Z / d Z^{V}\right)>0$. All of the above arguments will still go through for $Z_{m l}$ of sufficiently small absolute value.

Q.E.D.

Proof of Proposition 4: If the firms preempt, they choose $Z^{V}$ so that

$$
U^{N}\left(Z^{V}\right)=U^{N}\left(Z\left(Z^{V}\right)\right)-m^{e}\left(Z^{V}\right)-f\left(N^{c}\right) \text {. }
$$

Note that the Lemma shows that $m^{2}\left(Z^{V}\right)<m^{*}(0)$ and that $Z\left(Z^{V}\right)>Z(0)$, so $U^{N}\left(Z\left(Z^{V}\right)\right)>U^{N}(Z(0))$.

Therefore

$$
U^{N}\left(Z^{V}\right)=U^{N}\left(Z\left(Z^{5}\right)\right)-m^{e}\left(Z^{V}\right)-f\left(N^{c}\right)>U^{N}(Z(0))-m^{e}(0)-f(N \rho
$$

Q.E.D. 


\section{BIBLIOGRAPHY}

Abolafia, Mitchel Y. "Self-Regulation as Market Maintenance," in Roger G. Noll, editor, Regulatory Policy and the Social Sciences, Berkeley, CA: University of California Press, 1985.

Alberini, Anna and David Austin. (1999) "On and Off the Liability Bandwagon: Explaining State Adoptions of Strict Liability in Hazardous Waste Programs," Journal of Regulatory Economics, 15:41-63.

Arora, Seema and Tim Cason. "An Experiment in Voluntary Environmental Regulation: Participation in EPA's 33/50 Program," Journal of Environmental Economics and Management, v. 28, 1995, pp. 271-286.

Arora, Seema and Subhashis Gangopadhyay, "Toward a Theoretical model of Emissions Control," Journal of Economic Behavior and Organization, v. 28, December 1995, pp. 289-309.

Ayres, Ian and John Braithwaite, Responsive Regulation: Transcending the Deregulation Debate, New York: Oxford University Press, 1992.

Bagnoli, Mark and Susan G. Watts. "Ecolabeling: The Private Provision of a Public Good," mimeo, Indiana University, May 1995.

Barnard, Jayne W., "Exxon Collides with the Valdez Principles," Business and Society Review, 1990, pp. 32-35.

Becker, Gary S., "A Theory of Competition Among Pressure Groups for Political Influence," The Quarterly Journal of Economics, August 1983.

Besanko, David, "Performance versus Design Standards in the Regulation of Pollution," Journal of Public Economics, v. 34, 1987, pp. 19-44.

Bittlingmayer, George, "The Application of the Sherman Act to the Smog Agreement," Antitrust Bulletin 32, 1987, pp. 371-400.

Boston, Gerald W. and M. Stuart Madden. (1994) Law of Environmental and Toxic Torts: Cases, Materials and Problems. St. Paul, MN: West Publishing Co.

Braeutigam, Ronald R. and James P. Quirk, "Demand Uncertainty and the Regulated Firm," International Economic Review, v. 25, (1984), pp. 45-60.

Cairncross, Francis, Costing the Earth, Harvard Business School Press, Cambridge, Massachusetts, 1992.

Caves, Richard E. and Marc J. Roberts, editors, Regulating the Product: Quality and Variety, Cambridge, MA: Ballinger Publishing Company, 1975. 
Clark, Helen, editor. Developing the Next Generation of The U.S. EPA 's 33/50 Program. A Pollution Prevention Research Project, mimeo, Duke University, Durham, N.C, July 1996.

Davies, Terry and Jan Mazurek. Industry Incentives for Environmental Improvement: Evaluation of U.S. Federal Initiatives, Washington, DC: Global Environmental Management Initiative, 1996.

Donnenfeld, Shabtai and Shlomo Weber. "Limit Qualities and Entry Deterrence," RAND Journal of Economics, v. 26, no. 1, Spring 1995, pp. 113-130.

Gilbert, Richard and Xavier Vives. "Entry Deterrence and the Free Rider Problem," Review of Economic Studies, v. 53, 1986, pp. 71-83.

Glazer, Amihai and Henry McMillan, "Pricing by the Firm under Regulatory Threat," Quarterly Journal of Economics, August 1992, pp. 1089-1099.

Hackett, Steve."Pollution-Controlling Innovation in Oligopolistic Industries: Some Comparisons Between Patent Races and Research Joint Ventures," Journal of Environmental Economics and Management 29, 1995, pp. 339-356.

Hall, Bob and Mary Lee Kerr. 1991-92 Green Index: A State-By-State Guide to the Nation's Environmental Health, Washington D.C.: Island Press, 1991.

Hamilton, James T. "Pollution as News: Media and Stock Market Reactions to the Toxics Release Inventory Data," Journal of Environmental Economics and Management, v. 28, 1995, pp. 98-113.

Henderson, J. Vernon. "State Attitudes Towards Air Quality Regulation," mimeo, Brown University, March 1994.

Holmes, Thomas J. (1998) "The Effect of State Policies on the Location of Manufacturing: Evidence from State Borders," Journal of Political Economy, 106: 667-705.

Hunt, Michael S., "Trade Associations and Self-Regulation: Major Home Appliances," in Richard E. Caves and Marc J. Roberts, editors, Regulating the Product: Quality and Variety, Cambridge, MA: Ballinger Publishing Company, 1975.

Kaserman, David L. and John W. Mayo, Government and Business: The Economics of Antitrust and Regulation, Fort Worth, TX: The Dryden Press, 1995.

Konar, Shameek and Mark A. Cohen, "Information as Regulation: The Effect of Community Right to Know Laws on Toxic Emissions," Journal of Environmental Economics and Management, v. 32, 1997, pp. 109-124.

Lyon, Thomas P., "Regulation with 20-20 Hindsight: Heads I Win, Tails You Lose?", RAND Journal of Economics, v. 22, 1991, pp. 581-595.

Lutz, Stefan, Thomas P. Lyon and John W. Maxwell. "Strategic Quality Choice with Minimum Quality Standards," forthcoming in the Journal of Industrial Economics. 
Maloney, Michael and Robert McCormick. "A Positive Theory of Environmental Quality Regulation," Journal of Law and Economics, 1982, 35: 99-123.

Peltzman, Sam, "Toward a More General Theory of Regulation," Journal of Law and Economics, v. 19, 1976, pp. 211-248.

Pirrong, Stephen Craig, "The Self-Regulation of Commodity Exchanges: The Case of Market Manipulation," Journal of Law and Economics, v. 38, 1995, pp. 141-206.

Smart, Bruce, Beyond Compliance: A New Industry View of the Environment, Washington, D.C.: World Resources Institute, 1992.

Stigler, George, "The Theory of Economic Regulation," Bell Journal of Economics and Management Science, v. 2, 1971, pp. 3-21.

Tirole, Jean, The Theory of Industrial Organization, Cambridge, MA: The MIT Press, 1989.

U.S. Environmental Protection Agency, "EPA's Voluntary Programs: A Summary List Prepared by The 33/50 Program," Washington, DC, June 1994.

Walley, Noah and Bradley Whitehead, "It's Not Easy Being Green," Harvard Business Review, May-June, 1994. 
1. Smart (1992), p. 200.

2. Wall Street Journal, March 9, 1995, p. C1.

3. Quoted in Hunt (1975), page 45.

4. When self-regulation involves restrictions on quantity or sales territory, the terms "cartel" and "collusion" are applied and antitrust investigation may be expected. A large body of economic literature is devoted to identifying when such activities reduce social welfare. Kaserman and Mayo (1995) provide a good overview of this research.

5. Self-regulation may increase consumer demand by reducing uncertainty about product quality or ensuring interoperability of the products of different firms. It may enhance employee satisfaction by improving the safety or other quality aspects of the workplace. It may also serve more strategic purposes, such as softening competition or preempting stricter government regulations. If self-regulation is more cost-effective than government regulation, firms might self-regulate even if doing so has no impact on the ultimate level of restraint required.

6. For a survey of corporate environmental programs, see Smart (1992). The idea that "pollution prevention pays" has been widely promoted in the popular and trade press. For example, Cairncross (1992) notes that firms may engage in the production of "green" products to serve a high margin market niche, and that a reputation for cleanliness may ease the burden of plant location.

7. Many of the opportunities for painless Pareto-improvements have already been implemented. For example, 3M's "Pollution Prevention Pays" program has reduced the company's emissions by over 1 billion pounds since 1975 , and has saved 3M roughly $\$ 500$ million in the process. Walley and Whitehead argue, however, that many recent corporate environmental initiatives have had negative effects on company profits, suggesting that most companies now face sharply rising costs should cleanup standards be further increased.

8. One could also devise a somewhat more complex model that subdivides consumers into groups according to their relative disutilities for price increases and for environmental degradation. Because all consumer groups will on balance align with either the firms (lobbying for weaker regulations) or environmentalists (lobbying for stronger regulations), including additional consumer groups would complicate the modeling but seems unlikely to generate substantial new insights.

9. Although there is a vast literature on the economics of regulation, we take the "economic theory of regulation" to mean the strand of the literature associated with the work of Stigler (1971), Peltzman (1976) and Becker (1983).

10. It is important to note that our paper differs sharply from some earlier work on corporate strategy in the regulatory arena. For example, Maloney and McCormick (1982) show that firms may benefit from regulation if it raises marginal cost more than average cost, thereby increasing firms' producer surplus. In our model, marginal costs do not change with output, so firms do not have the Maloney and McCormick motive for seeking regulation. Indeed, in our model, firms only self-regulate to avoid government regulation. In addition, because we assume an oligopoly structure with no entry, firms have no incentive to lobby for regulation in order to increase entry barriers.

11. See for example Caves and Roberts (1975), Abolafia (1985) Pirrong (1995) and Ayres and Braithwaite (1992).

12. Arora and Gangopadhyay (1995) present a model where firms voluntarily reduce emissions of pollutants to attract "green" consumers. Bagnoli and Watts (1995) perform a similar analysis, and show that voluntary reductions generally cannot achieve the socially optimal level of abatement. Lutz, Lyon and Maxwell (forthcoming) study a vertical differentiation model with minimum quality standards and show that high-quality firms may have incentives to act strategically so as to shape future regulatory requirements. 
13. See Tirole (1989), chapter 8 , for a good overview.

14. Tirole (1989), section 8.3, presents a taxonomy of business strategies based upon animal analogies such as the "fat cat effect" and the "puppy dog ploy."

15. Note also that, unlike Gilbert and Vives (1986) or Donnenfeld and Weber (1995), our oligopolists never have an incentive to engage in excessive (i.e., Pareto-dominated levels of) entry deterrence, since individual firms do not obtain private benefits from voluntary abatement.

16. By assuming homogeneous products, we in effect assume that consumers cannot observe the emissions of an individual firm, though they may be able to observe aggregate environmental damage (e.g., air quality in the Los Angeles basin or water quality in the Great Lakes).

17. Because the firms are symmetric, the level of $\mathrm{Z}$ determined in stages 1 and 2 of the game is the same for all firms and we treat it as a scalar; we avoid vector notation for notational simplicity.

18. Obviously self-regulation looks even better if it is cheaper than government regulation.

19. We assume the existence of a unique pure-strategy equilibrium. See Tirole (1989), pp. 224-226 for conditions guaranteeing such an equilibrium exists, and further references on the subject.

20. While environmental groups and trade associations may coordinate the collection of funds from members, we emphasize the fact that the financial contributions of members are made individually and on a non-cooperative basis.

21. Because firms are symmetric and there is no possibility of entry, it is not profitable to lobby for stricter regulations as a means of raising rivals' costs.

22. These costs are often very high due to the incomplete state of scientific knowledge and its inaccessibility to those who are not experts in the relevant fields.

23. The additive form of $Z(M, L)$ is consistent with the application of a regulatory design standard requiring all firms to utilize a prescribed abatement process regardless of their existing emissions levels. As will be seen in Proposition 2, this gives oligopolistic firms an incentive to free-ride on industry-wide self-regulatory efforts, since they can gain a cost advantage by refusing to take voluntary abatement measures.

24.See Tirole (1989), p. 327, for further discussion of the terms "tough" and "soft" in multistage commitment games.

25. Bittlingmayer (1987) discusses a case in which automobile manufacturers were charged with colluding to reduce research and development expenditures on pollution abatement technologies. We discuss this case further in section IV.

26. In surveying a group of firms, some of which participated and some of which declined to participate in the EPA's voluntary "33/50" program, Clark (1996), p. 23, notes that "One of the most significant findings of our study was the identification of a potentially more positive response from some companies for a pollution prevention program sponsored by the company's trade association."

27. Proofs of propositions 1 and 2 are straightforward but tedious; they are available upon request from the authors.

28. Numerical examples show that either case can easily occur. 
29. Recall that $Z_{1},<0$, so the right-hand side of (13) is negative.

30. Of course, the number of firms and consumers still affects the equilibrium of the influence game through the left-hand side of (13), as discussed above.

31. In a model of multiple interest groups, one might wonder if environmentalists could impose regulations more stringent than socially optimal. This is unlikely in our interest-group model, however. Assuming there are more environmentalists than corporations, environmentalists would still suffer greater free-rider problems than firms. Furthermore, consumers who do not care about the environment would side with firms, strengthening firms in the influence game. Thus, the conditions that give rise to Proposition 3 would continue to hold.

32. Davies and Mazurek (1996), Chapter 1, p. 12.

33. A variety of factors may affect the rate of emissions reductions. For example, it is difficult to distinguish the potential role of technological change in making abatement less costly. There is no reason to believe that states differ in their access to new technology, however, so this factor is unlikely to explain cross-sectional variation in abatement. Another potential factor is the role of "green" consumers who are willing to pay a premium for environmentally-friendly products. As is discussed below, however, most of the industries releasing our toxic chemicals produce intermediate products such as chemicals, plastics or metals, which are not directly purchased by consumers, and are unlikely to be greatly affected by "green" consumer demand. Furthermore, products produced in a given state need not be sold there, so green consumers are unlikely to have a significant effect on voluntary abatement in their home state.

34. Davies and Mazurek (1996), Chapter 1, p. 15.

35. In February 1991, the EPA announced the "33/50 Program," a voluntary scheme designed to induce firms to cut their emissions of 17 key toxic chemicals $33 \%$ by 1992 and $50 \%$ by 1995 , relative to a 1988 baseline, by providing some favorable publicity and some limited technical assistance. The EPA has been criticized for the program's weak incentives (there are no penalties for failure to participate or failure to achieve the stated goals), and for overstating its results. Nevertheless, the existence of the program may have signalled an increased threat of federal regulation for these chemicals: emissions of the 33/50 chemicals fell $42 \%$ from 1991 to 1994, while emissions of all other TRI chemicals fell only 22\%. For an overview of the performance of the 33/50 Program, see Davies and Mazurek (1996).

36. Risk assessment data are taken from www.scorecard.org, a website on toxic chemical emissions maintained by the Environmental Defense Fund. To create our toxicity weighting, we divided each chemical's risk value by the average risk value for all seventeen toxic chemicals for both inhalation and ingestion risks. We then averaged these two normalized values across inhalation and ingestion risk. A few chemicals had only a risk value for either inhalation or ingestion, but not both, in which cases we simply used the one measure available.

37. Henderson (1994) finds that states with large land areas and low mean elevations incur greater expenditures on pollution abatement.

38. According to Boston and Madden (1994, p. 1), the most frequently used theories of legal liability in environmental and toxic torts cases are nuisance, trespass, negligence, strict liability for abnormally dangerous activities, and statutory strict liability.

39. These laws ensure non-union employees the right to work at companies within the state, thus reducing the bargaining power of unions.

40. Alberini and Austin (1999) present an interesting empirical analysis of states' hazardous waste liability regimes. 
41. These last four measures are from Hall and Kerr (1991).

42. We also performed a regression, not presented here, that included a variable interacting the presence of a rightto-work law with the initial level of toxicity-weighted emissions per value of shipments; this variable was intended to parallel our other interaction variable. The results confirm that states with pro-business attitudes engage in less voluntary pollution abatement and that states with larger environmental group membership show more voluntary abatement. 
Toxic Emissions vs. Manufacturing Shipments

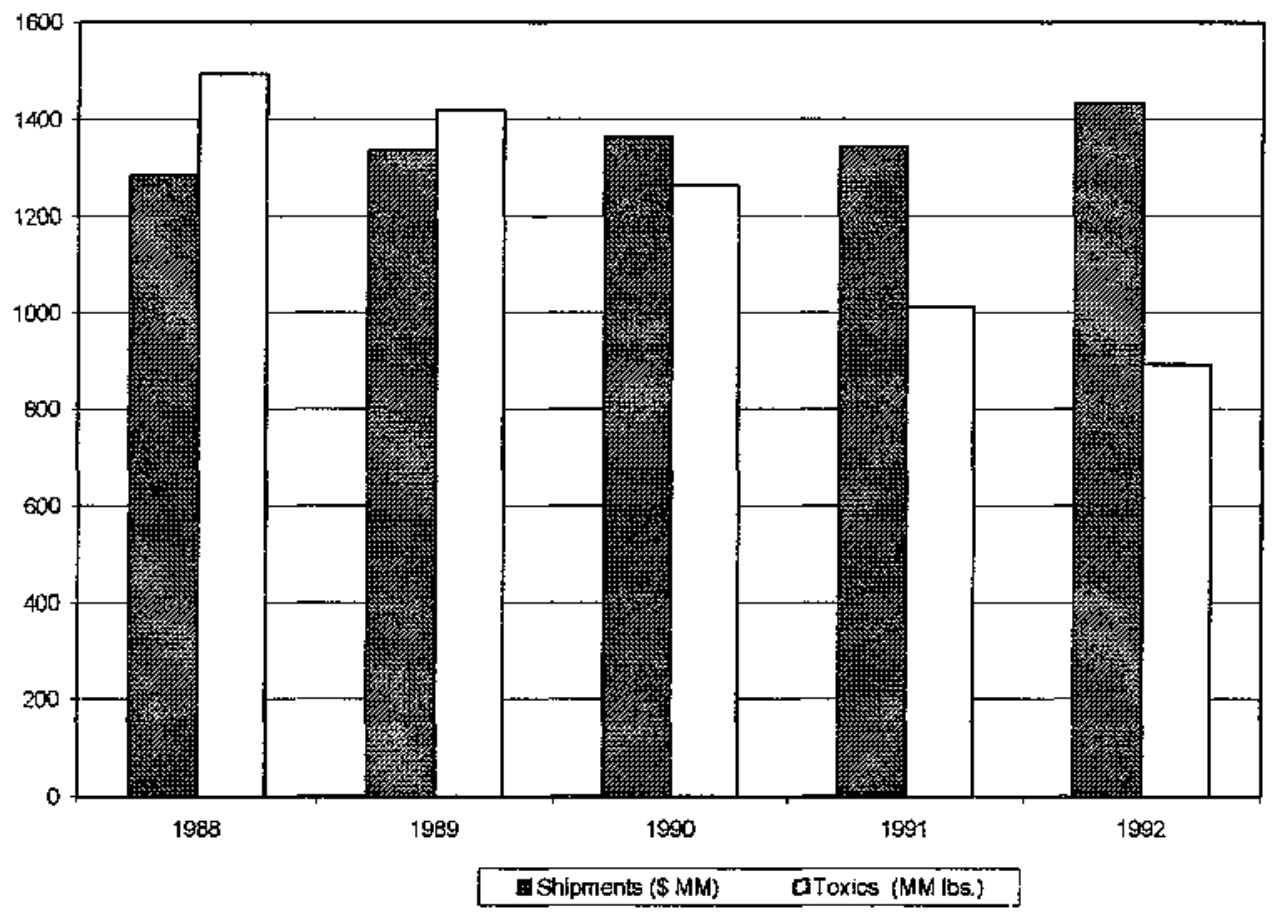

Figure 1: Total Emissions of 17 Toxic Chemicals vs.

Value of Shipments from 7 U.S. Manufacturing Industries, 1988-1992 


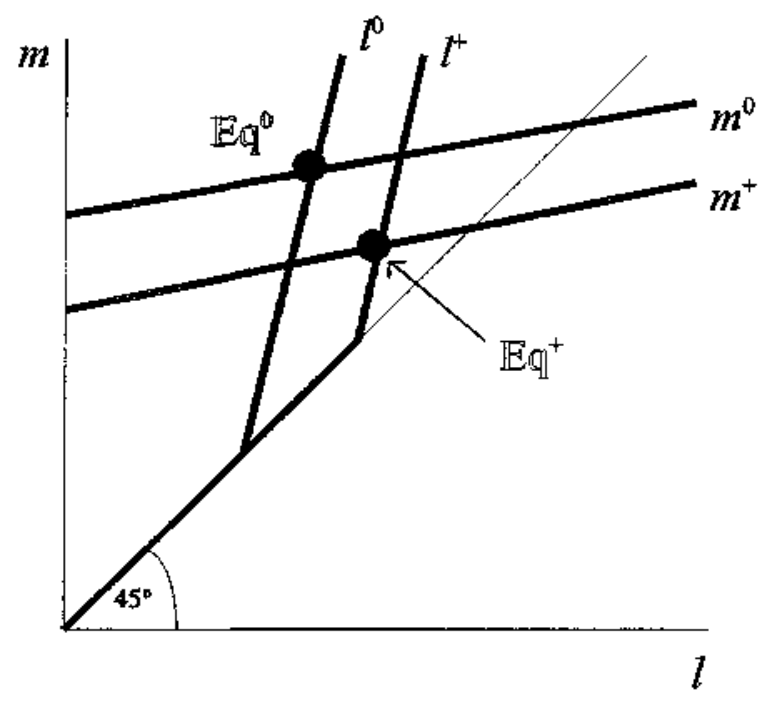

Figure 2: Firm (l) and Consumer $(m)$ Reaction Functions in the Influence Game 


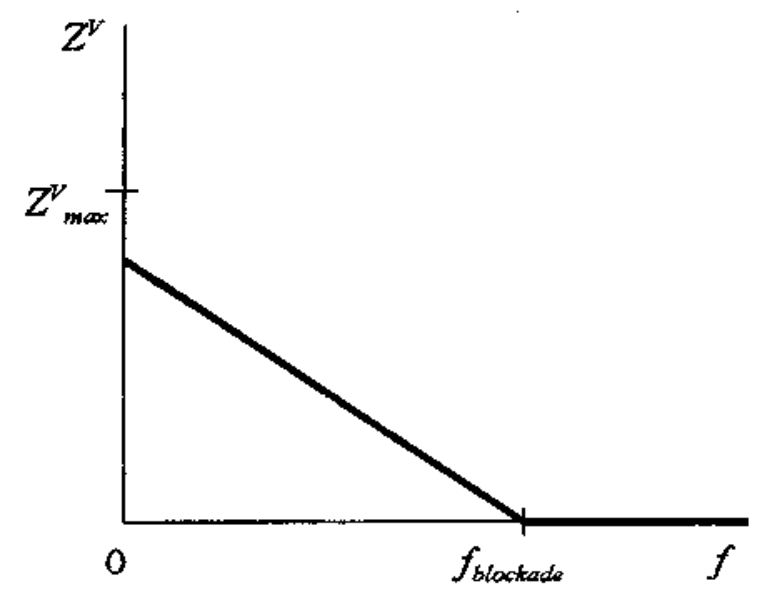

Figure 3 A: Optimal Voluntary Abatement $Z^{v}$ if Preemption is Profitable Even when Consumer Fixed Costs/are Zero

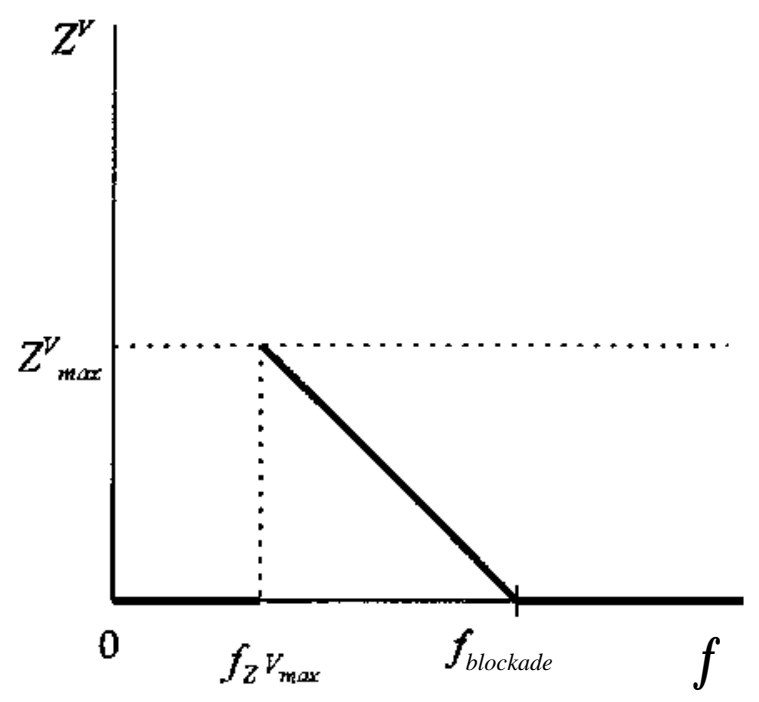

Figure 3B: Optimal Voluntary Abatement $Z^{v}$ if Preemption is Unprofitable when Consumer Fixed Costs/are Zero 
Table 1: 17 Key Toxic Chemicals

\begin{tabular}{|lrr|}
\hline & $\begin{array}{r}\text { Inhalation } \\
\text { non-cancer } \\
\text { risk value* } \\
\left(\mathrm{ug} / \mathrm{m}^{3}\right)\end{array}$ & $\begin{array}{l}\text { Ingestion } \\
\text { non-cancer } \\
\text { risk value* } \\
(\mathrm{mg} / \mathrm{kg} \text {-day })\end{array}$ \\
1,1,1-Trichloroethane & 1000 & 0.5 \\
Benzene & 60 & $\mathrm{n} / \mathrm{a}$ \\
Cadmium & 0.01 & 0.0005 \\
Carbon Tetrachloride & 40 & 0.0007 \\
Chloroform & 300 & 0.01 \\
Chromium & $\mathrm{n} / \mathrm{a}$ & 0.005 \\
Cyanide & $\mathrm{n} / \mathrm{a}$ & 0.02 \\
Dichloromethane & 300 & 0.06 \\
Lead & 0.15 & 0.0000785 \\
Mercury & 0.3 & 0.0003 \\
Methyl Ethyl Ketone & 1000 & 0.6 \\
Methyl Isobutyl Ketone & 80 & 0.08 \\
Nickel & 0.05 & 0.02 \\
Tetrachloroethylene & 40 & 0.01 \\
Toluene & 400 & 0.2 \\
Trichloroethylene & 600 & $\mathrm{n} / \mathrm{a}$ \\
Xylene (mixed isomers) & 200 & 2 \\
\hline
\end{tabular}

* These measures provide a standardized estimate of the amount of a given substance that must be inhaled or ingested in order to produce a given risk of harmful health effects. 
Table 2

Summary Statistics

Variable Definition

Tox/Value 1988 Toxicity-weighted pounds of 17 toxic chemicals released per $\$ 000$ of shipments (deflated) from 7 key manufacturing industries in 1988

Tox/Value 92-88 Change in Tox/Value from 1988 to 1992

Population density Population per square mile average for 1988 to 1992

Water Area Surface water area of state in square miles

Mean

Std. Dev.

Min. Max.

Mean Elevation
Temperature
Greens/capita

Mean elevation of state in feet

July daily maximum temperature

Members of NRDC and Sierra Club per thousand state residents, averaged over 1988-1992

\begin{tabular}{|c|c|c|c|}
\hline 151.647 & 485.827 & 0.786 & 3031.53 \\
\hline-43.697 & 258.093 & -1425.69 & 933.939 \\
\hline 0.166 & 0.233 & 0.001 & 1.042 \\
\hline 5039 & 13027 & 145 & $8605 \mathrm{I}$ \\
\hline 543.1 & 552 & 18 & 2074 \\
\hline 86.154 & 6.164 & 62.7 & 105.9 \\
\hline 2.233 & 1.318 & 0.494 & 7.11 \\
\hline 13947 & 2244.5 & 9972 & 20158.8 \\
\hline 19.754 & 3.71 & 12.3 & 27.2 \\
\hline 50.718 & 18.301 & 9.9 & 90.4 \\
\hline 44.76 & 14.4 & 23.1 & 77.4 \\
\hline 1.113 & 0.741 & 0.26 & 3.87 \\
\hline 0.72 & 0.45 & 0 & 1 \\
\hline 2.646 & 0.874 & 0 & 1 \\
\hline 0.42 & 0.496 & 0 & 1 \\
\hline 261.35 & 263.461 & 5 & 1049 \\
\hline 26 & 33.9 & 0.156 & 1 \\
\hline
\end{tabular}

State income per capita in $\$ 1987$ averaged over 1988-1992

Education Percentage of state population with a bachelor's degree or higher in 1990

LCV 1985-1990 League of Conservation Voters' rating of state's Congressional delegation over 1985-1990

Policy Initiatives Institute for Southern Studies' index of state performance on 67 policies

Spending on Air

Quality Per capita spending in fiscal 1988 for state programs to administer clean air laws

Strict $=1$ if state imposed strict liability for toxic waste cleanup in 1991 or before

Lawyers per capita Number of lawyers per thousand population in 1990

Right-to-Work $\quad=1$ if state has a right-to-work law

Plants Number of plants emitting our 17 selected toxic chemicals in 1988

Shipments Real value of shipments from 7 key manufacturing industries (\$MM) 
Table 3: Reductions in Toxic Emissions/Value of Shipments from 1988-1992

\begin{tabular}{|c|c|c|}
\hline Variable & (1) & (2) \\
\hline MT dummy & $\begin{array}{l}2941,751^{* * * *} \\
(21.415)\end{array}$ & $\begin{array}{l}2917.615^{* * *} \\
(47.493)\end{array}$ \\
\hline Water area & $\begin{array}{l}.00129^{\circ} \\
(1.824)\end{array}$ & $\begin{array}{l}.00102 \\
(1.643)\end{array}$ \\
\hline Mean elevation & $\begin{array}{l}.00127 \\
(.114)\end{array}$ & \\
\hline Temperature & $\begin{array}{l}5.4107^{*} \\
(1.827)\end{array}$ & $\begin{array}{l}4.9466^{*} \\
(1.679)\end{array}$ \\
\hline Population density & $\begin{array}{l}-.7561 \\
(-.039)\end{array}$ & \\
\hline Incone & $\begin{array}{l}-.0029 \\
(-.657)\end{array}$ & \\
\hline Greens/capita & $\begin{array}{l}{[1.4223} \\
(1.504)\end{array}$ & $\begin{array}{l}12.0738^{* *} \\
(2.334)\end{array}$ \\
\hline Education & $\begin{array}{l}.0447 \\
(.018)\end{array}$ & \\
\hline Greens*(Tox/Value 1988) & $\begin{array}{l}-.2783^{* * *} \\
(-6.974)\end{array}$ & $\begin{array}{l}-.2847^{* * *} \\
(-31.983)\end{array}$ \\
\hline Number of plants & $\begin{array}{l}.0577^{*} \\
(1.782)\end{array}$ & $\begin{array}{l}.05669^{*} \\
(1.711)\end{array}$ \\
\hline Shipments & $\begin{array}{l}-.634^{* *} \\
(-2.255)\end{array}$ & $\begin{array}{l}-.613^{* *} \\
(-2.062))\end{array}$ \\
\hline Tox/Value 1988 & $\begin{array}{l}-.0224 \\
(-.171) \\
\end{array}$ & \\
\hline Right to Work & $\begin{array}{l}9.8227 \\
(.938)\end{array}$ & $\begin{array}{l}5.7535 \\
(.550)\end{array}$ \\
\hline Strict Liability & $\begin{array}{l}7.9086 \\
(.937) \\
\end{array}$ & $\begin{array}{l}9.600 \\
(1.104) \\
\end{array}$ \\
\hline Lawyers per Capita & $\begin{array}{l}1.5183 \\
(.234)\end{array}$ & \\
\hline LCV $1985-90$ & $\begin{array}{l}.2647 \\
(.717)\end{array}$ & \\
\hline Policy Initiatives & $\begin{array}{l}.3332 \\
(.898)\end{array}$ & \\
\hline Spending on air quality & $\begin{array}{l}8.9101 \\
(1.362)\end{array}$ & $\begin{array}{l}6.3541 \\
(1.110) \\
\end{array}$ \\
\hline Toxjc Cuts Dummy & $\begin{array}{l}-2.5369 \\
(-.317)\end{array}$ & \\
\hline Constant & $\begin{array}{l}-504.7815^{*} \\
(-1.868)\end{array}$ & $\begin{array}{l}-470.1004^{*} \\
(-1.745)\end{array}$ \\
\hline Observations & 50 & 50 \\
\hline Adjusted R-squared & .9791 & .9834 \\
\hline
\end{tabular}

